\title{
DEVELOPING AND MEASURING ATTENTION IN BOXERS: MIXED COACHES’ EXPERTISE AND REACTION TIME MEASURES
}

\author{
Aleksandrs Kolesovs \\ University of Latvia, Latvia \\ Deniss Salkovs \\ Boxing Club "Latvijas Cimdi”, Latvia
}

Aleksejs Blinovs

Freelance, Latvia

\begin{abstract}
This study explored the problem of attention and its development in young boxers. A rapidly changing situation and a high level of traumatization in boxing are demanding the development of athletes' attention. Focusing on technical or motivational training is among the reasons for underestimating the development of attentional skills. Study 1 involved seven expert coaches (males, mean age 45.4, mean working experience 20.3 years). The results revealed a relatively high assessment of the psychological component of training and a low agreement on the development of attentional skills. Coaches indicated that testing is the best measurement of attention. Study 2 focused on the measurement of reaction time (RT) in young boxers. Simple and complex RT of nine athletes, aged 12 to 15 (33\% females), were assessed before and after the 15 minutes long warm-up. The results demonstrated no significant change in boxers' simple $R T$ and a decrease (about $30 \mathrm{~ms}$ ) in complex RT after the warm-up. The feedback was provided for athletes and their coaches. A contrast appeared between coaches' view of well-known exercises for developing attention and their question "Could you suggest some exercise?" Simultaneously, coaches suggested a more specific RT measurement, including the full time of a punch.
\end{abstract}

Keywords: attention, boxing, coaches' expertise, reaction time.

\section{Introduction}

Boxing is among sports requiring athletes' attention during their adaptation to rapidly changing situations (Wang, 2016). A loss of focused attention could result in brain injury with cumulative negative effects (Maroon, Winkelman, Bost, Amos, Mathyssek, \& Miele, 2015; McKee et al., 2013; Rabadi \& Jordan, 2001). Traumatization of young athletes (e.g., Moser, Schatz, \& Jordan, 2005) raised recommendations to participate in alternative sports or to oppose boxing as a sport for any child or adolescent (Purcell \& LeBlanc, 2012). It indicates that the development of attentional skills in boxers seems a crucial task for more effective 
and healthy functioning. Simultaneously, coaches' focusing on technical (Wang, 2016) or motivational (Nazarenko \& Kolesnik, 2017) training could be a reason for the underestimation of the development of attention. The current study aimed at revealing experienced boxing coaches' views of attention among athletes' characteristics, possible ways of its development, and providing them feedback, based on a measure of athletes' reaction time (RT).

\section{Study 1}

The high complexity of boxing as an open-skill sport (Wang, 2016) demands activation of any attentional sub-process: attentional orienting and selective, divided, and sustained attention (Coull, 1998). They direct athletes' attention, focus it on a particular target, distribute cognitive resources between targets, and maintain attentional functioning, respectively (for a review, Memmert, 2009).

Training of attention challenges coaches and athletes in various sports (Wang, 2016). Differences between levels of physical fit and athletes' expertise in some aspects of attentional and perceptual functioning (e.g., Nougier, Ripoll, \& Stein, 1989; Reigal, Barrero, Martin, Morales-Sánchez, de Mier, \& HernándezMendo, 2019; Vaeyens, Lenoir, Williams, Mazyn, \& Philippaerts, 2007) are in line with revealed effects of attention training by different methods (Tang \& Posner, 2009). Tang and Posner (2009) suggested a combination of effortful attention training, aimed at the executive attentional network (e.g., Posner, Sheese, Odludas, \& Tang, 2006), and attention state training focused at a balanced body-mind state. Simultaneously, a limited transfer of trained cognitive skills and diminishing skills without practice lead to the conclusion that individuals improve predominantly on what they practice (Diamond \& Ling, 2016).

Coaches' views of training became the focus of the first step of the study. We have selected the method of the expert interview (e.g., Bogner \& Menz, 2009) as appropriate for a more detailed exploration of views on the development of attentional skills. It was expected that the results could reveal the level of agreement on some key points in the practice, weak points in the development of athletes' attention, and possible solutions.

\section{Method}

Participants. Experts were selected in accordance with the following criteria: no less than 10 years of coaching experience, involvement in coaching young (12-15 years old) and adult boxers, higher education, and high achievement of athletes (e.g., champions of Latvia). After applying these criteria, coaches were invited to an interview. Coach's disagreement to participate was an exclusion criterion. As a result, seven coaches were included in the expert panel. Their age 
was 31 to $58(M=45.4, S D=10.2$ years $)$. Coaches' working experience was from 10 to 35 years $(M=20.3, S D=9.2$ years $)$. All the coaches were males.

Materials. The systematizing expert interview (Bogner \& Menz, 2009) was developed for the study. The interview was planned during the preparatory phase, including a discussion of a boxing coach and a psychologist on the topic under investigation. During this phase, questions regarding attention and its training were formulated.

The semi-structured interview included three structured questions and two open questions. The question regarding psychological, technical, physical, and tactical training required ranking these elements from the first to the fourth place. Coaches also assessed the significance of attention, memory, goal-orientation, discipline, courage, fighting spirit, willpower, and persistence in boxing by a seven-point scale from 1 (not important) to 7 (very important). In addition, they ranked 13 exercises (e.g., throwing the tennis ball to a partner, repeating partner's movements, reacting to a signal, playing table tennis) and aspects of practice (e.g., sparring, boxing competitions). Open questions were: "How can you assess athletes' attention?" and "Could you suggest any additional exercise for the development of attentional skills?” There was also an opportunity to add any comment at the end of the interview.

Procedure. Data were collected via personal interviews. The interviewer was a co-expert in the field. It ensured symmetrical interaction during the interview.

\section{Results}

Coaches' ranked the technical aspect of practice as the most significant for young athletes (mean rank was 1.86). It was followed by physical (2.14) and psychological (2.29) training. The last aspect was tactical training (3.71). Simultaneously, the psychological aspect was assessed as the most important by two coaches and as the second by three coaches. It indicated the relative significance of this aspect and a low level of agreement among coaches. Assessed by Kendall's W, the general level of agreement on aspects of practice was .41, $p=.034$.

Table 1 demonstrates the relative significance of attention among other athlete's characteristics. Different aspects of motivation and self-regulation were assessed higher than cognitive (attention and memory) aspects. 
Kolesovs et al., 2020. Developing and Measuring Attention in Boxers: Mixed Coaches' Expertise and Reaction Time Measures

Table 1 Assessment of the significance of athletes' characteristics by coaches $(N=7)$

\begin{tabular}{|l|c|c|c|}
\hline \multicolumn{1}{|c|}{ Characteristic } & Rank & $M$ & $S D$ \\
\hline Fighting Spirit & 1 & 6.86 & 0.34 \\
\hline Discipline & 2 & 6.57 & 1.13 \\
\hline Goal-Orientation & $3-4$ & 6.29 & 0.76 \\
\hline Willpower & $3-4$ & 6.29 & 1.13 \\
\hline Courage & 5 & 6.00 & 0.58 \\
\hline Persistence & 6 & 5.86 & 0.90 \\
\hline Attention & $7-8$ & 5.14 & 0.90 \\
\hline Memory & $7-8$ & 5.14 & 1.46 \\
\hline Autonomy & 9 & 4.86 & 1.35 \\
\hline
\end{tabular}

Ranking of exercises for the development of attentional skills (Table 2) demonstrated that coaches emphasize the importance of warm-up exercises and exercises in pairs, while the elements of practice (sparring and competition) are ranked low. The level of coaches' agreement was also relatively low, Kendall's $\mathrm{W}=.35, p<.001$.

Table 2 Ranking of exercises and elements of boxing practice by coaches $(N=7)$

\begin{tabular}{|l|c|}
\hline \multicolumn{1}{|c|}{ Exercises and boxing practice } & Mean Rank \\
\hline Reaction to coach's signal during the warm-up & 3.00 \\
\hline Mirror training (“School”) & 3.57 \\
\hline Repeating partner's movements & 4.43 \\
\hline Throwing two tennis balls in pairs & 5.79 \\
\hline Throwing the tennis ball against the wall & 6.43 \\
\hline Technical exercises in pairs & 6.86 \\
\hline Reacting to light signals & 6.93 \\
\hline Performing the Schulte Table Test & 7.71 \\
\hline Table tennis & 7.79 \\
\hline Performing the Stroop Test & 8.36 \\
\hline Sparring & 9.00 \\
\hline Chess play & 10.21 \\
\hline Boxing competition & 10.93 \\
\hline
\end{tabular}

The results of a qualitative content analysis revealed three main categories in coaches' views on the assessment of athletes' attention: testing ("tests" - 4 times; "special apparatus"), repeating and recognition ("repeat an exercise"; "recognized actions"; "reporting recognized failures”), and reacting to a signal ("reacting to an audial signal"; "reacting to a coach's signal”).

Additional exercises for the development of athletes' attention revealed coaches' view of a relatively big number of exercises ("there are a lot of them"; “different exercises"), a need for modern devices for its development ("modern 
devices"; “technical tools for development”), and suggested some exercises not mentioned in the list ("cross-country running in the wood"; "reacting to a ball or movement from behind”; "concentration exercises”).

\section{Discussion}

The highest position of technical skills in coaches' views confirms the problem in the development of attentional skills (Wang, 2016). Coaches' assessment of the significance of psychological aspects in young boxers' practice is also relatively high. Simultaneously, the level of agreement among coaches was low, and attention was evaluated lower than motivational components of athletes' practice. Focusing on boxers' motivation was also found in other studies (e.g., Nazarenko \& Kolesnik, 2017).

Coaches' answers to open questions revealed that the assessment of athletes' attention should include testing of reaction to signals and counting errors during this process. We have developed a measurement tool in the next step of the study.

\section{Study 2}

Based on our qualitative findings and previous studies in broad populations of athletes and non-athletes (e.g., Fard, Boroujeni, \& Lavender, 2019; Larson, Sherlin, Talley, \& Gervais, 2012; Lesiakowski, Zwierko, \& Krzepota, 2013; Reigal et al., 2019; Surina-Marysheva, Malkov, \& Yermolaeva, 2016), we have selected the measurement of RT as the most suitable for the assessment of boxers' attention. Measurements of RT are useful for the investigation of attentional processes, modulating individual reactions (Coull, 1998; Posner et al., 2006). RT is also ecologically valid for a broad number of open-skills sports, referred to as reaction-based sports (Wang, 2010).

RT represents the speed of the sensorimotor circle, composed by detection of the stimulus, an afferent transfer of information, generation of the response, and a motoric response (Adleman et al., 2016). As Wang (2010) pointed, premotor (cognitive) RT could be improved to a greater extent than the motor (motoric response) RT. Shortening RT by improvement decision-making speed and focusing and distribution of the attention could fill a performance gap at the high-level competition, associated with high pressure, fast pace, and unpredictable situations (Wang, 2010). However, the highly individualized training program for an elite professional boxer (Larson et al., 2012) revealed no significant reduction in RT and a significant improvement only in the level of accuracy (making significantly fewer errors).

There are two main kinds of RT tasks - simple and complex (e.g., Reigal et al., 2019). The first implies a simple reaction to a single stimulus. The second 
involves the identification and selection of a response to various (at least two) stimuli. Studies demonstrated relative stability of simple RT after the warm-up or a short intervention (e.g., Balilionis et al., 2012; Perrier, Pavol, \& Hoffman, 2011). It lengthens in association with fatigue (Fard et al., 2019), as also shown in boxers after sparring (Hukkanen \& Häkkinen, 2017). Complex RT is less investigated in association with its change (e.g., Niederer et al., 2019). Therefore, data on changing athletes' complex RT will be helpful for further investigation. In this exploratory study, we have developed a device for measuring simple and complex $\mathrm{RT}$ and tested young boxers before and after the 15-minutes-long warm-up.

\section{Method}

Participants. Nine athletes, aged 12 to 15 ( $\mathrm{M}=13.9$, SD $=1.3,33 \%$ females), participated in the study. Athletes' participated in the study after signed informed consent was received from their parents.

Measures. The measurement of RT was performed by a device based on an 8-bit AVR programmed microcontroller Arduino Nano, processor ATmega328P, frequency $16 \mathrm{MHz}$, operating voltage $5 \mathrm{~V}$. The technical characteristics of its connection to the laptop followed the USB 2.0 standard for external devices. The terminal included two signal buttons, operated by the tester, the red and blue lightdiodes, and two reaction buttons, operated by the athlete (Figure 1).

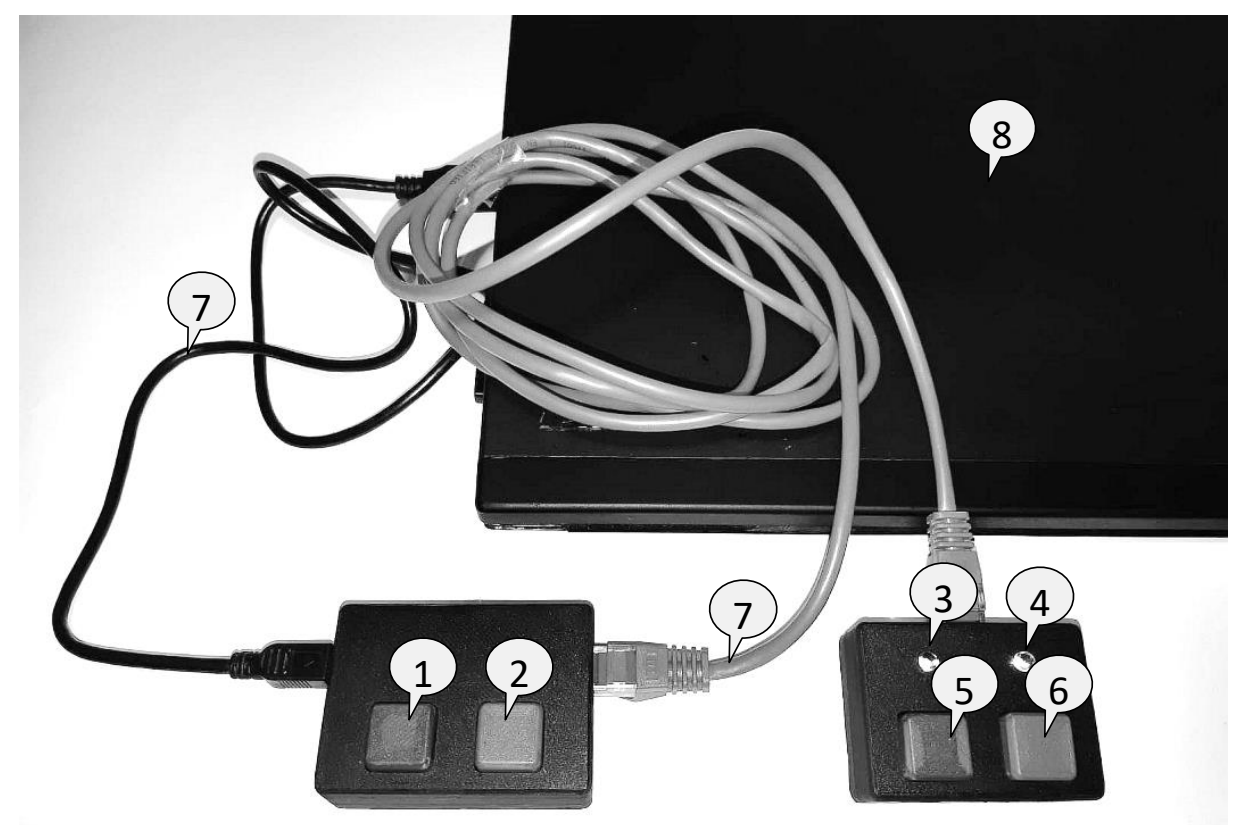

Figure 1 Terminal for measuring reaction time: 1 - blue signal button; 2 - red signal button; 3 - blue light-diode; 4 - red light-diode; 5 - blue reaction button; 6 - red reaction button; 7 - connection wires; 8 - laptop (developed by authors) 
A two-channel digital oscilloscope Hantek DSO5102B (100MHz bandwidth, 1GSample/s) was applied for calibration of the device. The results for both signals indicated that $80 \%$ of measures were equal, and $20 \%$ of measures differ for no more than $1 \mathrm{~ms}$ (the step in counting RT).

Procedure. A simple reaction task included measuring athletes' RT after the red signal was presented (red diode on). Time intervals between signals varied from 1 to 3 seconds to minimize the effect of learning. At least 10 signals were presented within this task.

A complex reaction task included measuring RT after the red or blue signal was presented. The selective reaction required pushing the red button in the case of the red signal and blue button for the blue one. Time intervals among signals were about 1 to 2 seconds. The sequence of signals included switching or repeating (up to 3 times) signals (e.g., Red-Blue-Red-Blue-Blue-Red-Red-BlueRed...). At least 20 signals were presented.

The first measurement was performed before the warm-up. The second measure was conducted after the 15 minutes long warm-up. The warm-up protocol included dynamic stretching and basic exercises. It started with basic exercises in movement followed by dynamic stretching and shadow boxing (3 minutes).

Statistical analysis was performed by IBM SPSS 22.0 package. Statistical power was calculated by R-package 'pwr'.

\section{Results}

A relatively low number of participants defined the use of a paired sample ttest as robust to small sample sizes. Figure 2 presents the means of simple and complex RT before and after the warm-up. The results demonstrated no significant change in simple RT after the warm-up, $t(8)=0.34, p=.741$. Athletes' complex RT decreased significantly after the warm-up, $t(8)=4.48, p=.002$. For this change, Cohen's d was 1.51 (inter-correlation between conditions $r(8)=.75$, $p=.020)$ and observed power was .87 .

For simple RT, the mean number of errors was $0.44(S D=1.33)$ before the warm-up and $0.33(S D=0.50)$ after it. The change was not significant, $t(8)=0.22$, $p=.834$. For complex RT, the mean number of errors was $1.44(S D=1.59)$ before the warm-up and $1.56(S D=1.81)$ after it, also demonstrating no significant change, $t(8)=-0.23, p=.824$. 


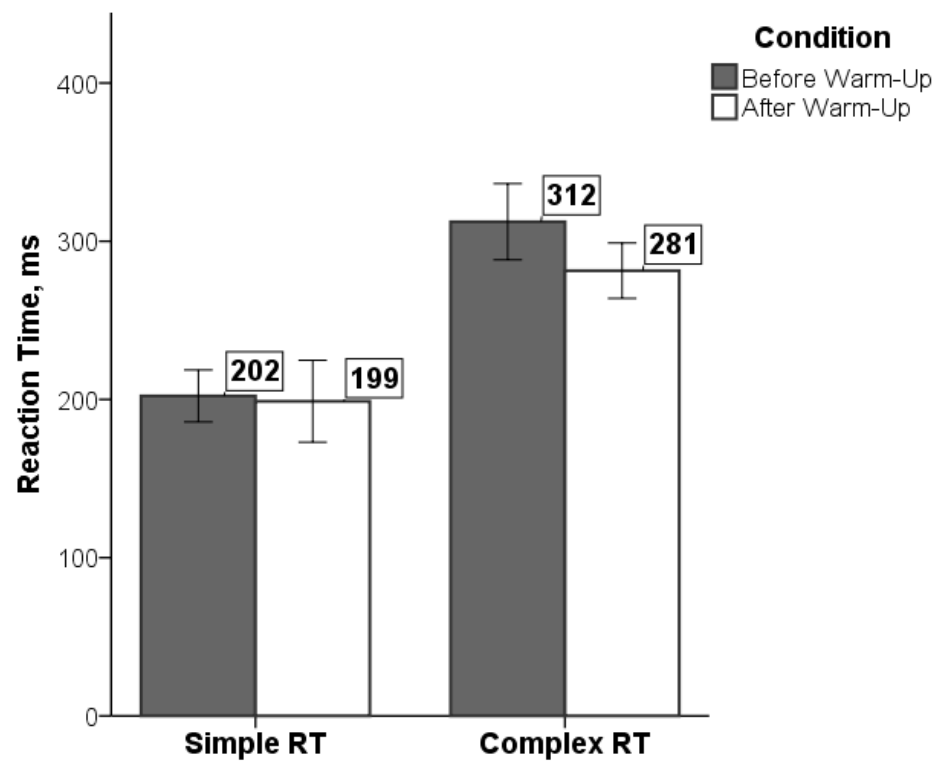

Figure 2 Simple and complex reaction time (RT) before and after the warm-up in young boxers $(N=9)$

\section{Discussion}

The results revealed a significant effect of the warm-up on complex RT and no effect on the simple RT. These findings confirmed the stability of simple RT after the short intervention (Balilionis et al., 2012; Perrier, Pavol, \& Hoffman, 2011). The level of simple RT was close to RT of skilled boxers aged 20-25 (Surina-Marysheva et al., 2016). Simultaneously, we have found an improvement in complex RT associated with decision making (Reigal et al., 2019). Physical conditioning could be considered among mechanisms for this improvement (Reigal et al., 2019).

The results of this part were discussed with two coaches. They have expected that the warm-up will not affect simple RT. And one of them expected the change in complex RT. In contrast to well-known exercises for developing attention, one of the coaches asked: “Could you suggest some exercise?” This question reflected a coach's interest in the development of boxers' attentional skills and some lack of effective instruments in their development. Also, both coaches suggested the measurement of RT, which includes the full punch in the assessed sensorimotor circle.

\section{General discussion}

Both parts of the study confirmed that objective measures form the basis for the feedback for athletes and coaches. We have developed a device for 
measurement two main kinds of RT associated with attentional processes (e.g., Reigal et al., 2019; Surina-Marysheva et al., 2016). The review of the literature and our findings demonstrate that a specific training system should be developed for the development of boxers' attentional skills. There is no simple way for the improvement of aspects of attention.

The exploratory nature of the study resulted in some limitations. Large effect size and sufficient statistical power confirmed the significance of the change in complex RT. Simultaneously, further study should involve a broader sample of young athletes, allowing testing an interaction between the task and warm-up. Longer trials will be useful for a more detailed exploration of the level of accuracy in RT tasks. A control group is needed for testing a possible effect of learning.

\section{Conclusions}

In sum, we have found signs of underestimation of the development of attention in boxers. We have developed a device for measuring simple and complex RT, which associates with attentional processes. The effect of the warmup on athletes' complex RT is the main quantitative finding and, simultaneously, a question for further investigation. The development of attentional skills and shortening RT remain the challenges for coaches and athletes.

\section{References}

Adleman, N.E., Chen, G., Reynolds, R.C., Frackman, A., Razdan, V., Weissman, D.H., ... Leibenluft, E. (2016). Age-related differences in the neural correlates of trial-to-trial variations of reaction time. Developmental Cognitive Neuroscience, 19, 248-257. DOI:10.1016/j.dcn.2016.05.001

Balilionis, G., Nepocatych, S., Ellis, C.M., Richardson, M.T., Neggers, Y.H., \& Bishop, P.A. (2012). Effects of different types of warm-up on swimming performance, reaction time, and dive distance. Journal of Strength and Conditioning Research, 26, 3297-3303. DOI:10.1519/JSC.0b013e318248ad40

Bogner, A., \& Menz, W. (2009). The Theory-Generating Expert Interview: Epistemological Interest, Forms of Knowledge, Interaction. In A. Bogner, B. Littig, \& W. Menz (Eds.), Interviewing Experts. (pp. 43-80). London: Palgrave Macmillan. DOI: 10.1057/9780230244276_3

Coull, J.T. (1998). Neural correlates of attention and arousal: Insights from electrophysiology, functional neuroimaging and psychopharmacology. Progress in Neurobiology, 55, 343361. DOI: 10.1016/S0301-0082(98)00011-2

Diamond, A., \& Ling, D.S. (2016). Conclusions about interventions, programs, and approaches for improving executive functions that appear justified and those that, despite much hype, do not. Developmental Cognitive Neuroscience, 18, 34-48. DOI:10.1016/ j.dcn.2015.11.005 
Fard, S.J., Boroujeni, S.T., \& Lavender, A.P. (2019). Mental fatigue impairs simple reaction time in non-athletes more than athletes. Fatigue: Biomedicine, Health \& Behavior, 7, 117-126. DOI:10.1080/21641846.2019.1632614

Hukkanen, E., \& Häkkinen, K. (2017). Effects of sparring load on reaction speed and punch force during the precompetition and competition periods in boxing. Journal of Strength and Conditioning Research, 31, 1563-1568. DOI:10.1519/JSC.0000000000001885

Larson, N.C., Sherlin, L., Talley, C., \& Gervais, M. (2012). Integrative approach to highperformance evaluation and training: Illustrative data of a professional boxer. Journal of Neurotherapy, 16, 285-292. DOI:10.1080/10874208.2012.729473

Lesiakowski, P., Zwierko, T., \& Krzepota, J. (2013). Visuospatial attentional functioning in amateur boxers. Journal of Combat Sports and Martial Arts, 4, 141-144. DOI:10.5604/20815735.1090659

Maroon, J.C., Winkelman, R., Bost, J., Amos, A., Mathyssek, C., \& Miele, V. (2015). Chronic traumatic encephalopathy in contact sports: A systematic review of all reported pathological cases. PLoS ONE 10(2), e0117338. DOI:10.1371/journal.pone.0117338

McKee, A.C., Stern, T.D., Nowinski, C.J., Stein, R.A., Daneshvar, D.H., Alvarez, V.E., ... Cantu, R.C. (2013). The spectrum of disease in chronic traumatic encephalopathy. Brain, 136, 43-64. DOI:10.1093/brain/aws307

Memmert, D. (2009). Pay attention! A review of visual attentional expertise in sport. International Review of Sport and Exercise Psychology, 2, 119-138. DOI:10.1080/17509840802641372

Moser, R.S., Schatz, P., \& Jordan, B.D. (2005). Prolonged effects of concussion in high school athletes. Neurosurgery, 57, 300-306. doi:10.1227/01.NEU.0000166663.98616.E4

Nazarenko, L., \& Kolesnik, I. (2017). Conditions for improving basic sports training of 13-14year-old boxers. Journal of Physical Education and Sport, 17, 2484-2494. DOI:10.7752/jpes.2017.04279

Niederer, D., Plaumann, U., Seitz, T., Wallner, F., Wilke, J., Engeroff, T., ... Banzer, W. (2019). How does a 4-week motor-cognitive training affect choice reaction, dynamic balance and cognitive performance ability? A randomized controlled trial in well-trained, young, healthy participants. SAGE Open Medicine, 7, 1-8. DOI:10.1177/2050312119870020

Nougier, V., Ripoll, H., \& Stein, J.-F. (1989). Orienting of attention with highly skilled athletes. International Journal of Sport Psychology, 20(3), 205-223.

Perrier, E.T., Pavol, M.J., \& Hoffman, M.A. (2011). The acute effects of a warm-up including static or dynamic stretching on countermovement jump height, reaction time, and flexibility. Journal of Strength and Conditioning Research, 25, 1925-1931. DOI: 10.1519/JSC.0b013e3181e73959

Posner, M.I., Sheese, B.E., Odludas, Y., \& Tang, Y.Y. (2006). Analyzing and shaping human attentional networks. Neural Networks, 19, 1422-1429. DOI:10.1016/ j.neunet.2006.08.004

Purcell, L.K., \& LeBlanc, C.M.A. (2012). Boxing participation by children and adolescents. Paediatrics \& Child Health, 17(1), 39. DOI:10.1093/pch/17.1.39

Rabadi, M.H., \& Jordan, B.D. (2001). The cumulative effect of repetitive concussion in sport. Clinical Journal of Sport Medicine, 11, 194-198. doi:10.1097/00042752-20010700000011

Reigal, R.E., Barrero, S., Martín, I., Morales-Sánchez, V., de Mier, R. J.-R., \& HernándezMendo, A. (2019). Relationships between reaction time, selective attention, physical 
Proceedings of the International Scientific Conference. Volume VII, May $22^{\text {th }}-23^{\text {th }}$, 2020. 84-94

activity, and physical fitness in children. Frontiers in Psychology, 10, e02278. DOI:10.3389/fpsyg.2019.02278

Surina-Marysheva, E.F., Malkov, V.P., \& Yermolaeva, E.N. (2016). Sensomotor integration features in skilled female boxers. Journal of Physical Education and Sport, 16(1), 24-27. DOI:10.7752/jpes.2016.01004

Tang, Y.Y., \& Posner, M.I. (2009). Attention training and attention state training. Trends in Cognitive Sciences, 13, 222-227. doi:10.1016/j.tics.2009.01.009

Vaeyens, R., Lenoir, M., Williams, A.M., \& Philippaerts, R.M. (2007). Mechanisms underpinning successful decision making in skilled youth soccer players: An analysis of visual search behaviors. Journal of Motor Behavior, 39, 395-408, DOI:10.3200/ JMBR.39.5.395-40

Wang, J. (2010). Strategies for filling a performance gap between practice and high-level competition. Journal of Physical Education, Recreation \& Dance, 81(6), 26-32. DOI:10.1080/07303084.2010.10598488

Wang, J. (2016). Key principles of open motor-skill training for peak performance. Journal of Physical Education, Recreation \& Dance, 87(8), 8-15. DOI:10.1080/ 07303084.2016.1216341 